Article

\title{
Evaluation of the Performance of Low-Cost Air Quality Sensors at a High Mountain Station with Complex Meteorological Conditions
}

\author{
Hongyong $\mathrm{Li}^{1}{ }^{1}$, Yujiao Zhu ${ }^{1, *}$, Yong Zhao ${ }^{2}$, Tianshu Chen ${ }^{1}$, Ying Jiang ${ }^{1}$, Ye Shan ${ }^{1}$, \\ Yuhong Liu ${ }^{1}$, Jiangshan $\mathrm{Mu}^{1}{ }^{1}$, Xiangkun Yin ${ }^{2}$, Di Wu ${ }^{2}$, Cheng Zhang ${ }^{3}$, Shuchun $\mathrm{Si}^{4}$, \\ Xinfeng Wang ${ }^{1} \mathbb{D}$, Wenxing Wang ${ }^{1}$ and Likun Xue ${ }^{1, *}$ \\ 1 Environment Research Institute, Shandong University, Qingdao 266237, China; \\ lihongyong0501@163.com (H.L.); tianshu129@163.com (T.C.); m15165122303@163.com (Y.J.); \\ 201712638@mail.sdu.edu.cn (Y.S.); liuyh13336300207@163.com (Y.L.); 201812878@mail.sdu.edu.cn (J.M.); \\ xinfengwang@sdu.edu.cn (X.W.); wxwang@sdu.edu.cn (W.W.) \\ 2 Taishan National Reference Climatological Station, Tai'an 271000, China; 13583815154@163.com (Y.Z.); \\ yinxiangkun@yeah.net (X.Y.); snail0516@gmail.com (D.W.) \\ 3 Tai'an Ecological Environment Command and Control Center, Tai'an 271000, China; chengzh6999@163.com \\ 4 School of physics, Shandong University, Jinan 250100, China; ssc@sdu.edu.cn \\ * Correspondence: zhuyujiao@sdu.edu.cn (Y.Z.); xuelikun@sdu.edu.cn (L.X.)
}

Received: 5 January 2020; Accepted: 16 February 2020; Published: 19 February 2020

check for updates

\begin{abstract}
Low-cost sensors have become an increasingly important supplement to air quality monitoring networks at the ground level, yet their performances have not been evaluated at high-elevation areas, where the weather conditions are complex and characterized by low air pressure, low temperatures, and high wind speed. To address this research gap, a seven-month-long inter-comparison campaign was carried out at Mt. Tai (1534 m a.s.l.) from 20 April to 30 November 2018, covering a wide range of air temperatures, relative humidities (RHs), and wind speeds. The performance of three commonly used sensors for carbon monoxide $(\mathrm{CO})$, ozone $\left(\mathrm{O}_{3}\right)$, and particulate matter $\left(\mathrm{PM}_{2.5}\right)$ was evaluated against the reference instruments. Strong positive linear relationships between sensors and the reference data were found for $\mathrm{CO}(r=0.83)$ and $\mathrm{O}_{3}(r=0.79)$, while the $\mathrm{PM}_{2.5}$ sensor tended to overestimate $\mathrm{PM}_{2.5}$ under high $\mathrm{RH}$ conditions. When the data at $\mathrm{RH}$ $>95 \%$ were removed, a strong non-linear relationship could be well fitted for $\mathrm{PM}_{2.5}$ between the sensor and reference data $(r=0.91)$. The impacts of temperature, $\mathrm{RH}$, wind speed, and pressure on the sensor measurements were comprehensively assessed. Temperature showed a positive effect on the $\mathrm{CO}$ and $\mathrm{O}_{3}$ sensors, $\mathrm{RH}$ showed a positive effect on the PM sensor, and the influence of wind speed and air pressure on all three sensors was relatively minor. Two methods, namely a multiple linear regression model and a random forest model, were adopted to minimize the influence of meteorological factors on the sensor data. The multi-linear regression (MLR) model showed a better performance than the random forest (RF) model in correcting the sensors' data, especially for $\mathrm{O}_{3}$ and $\mathrm{PM}_{2.5}$. Our results demonstrate the capability and potential of the low-cost sensors for the measurement of trace gases and aerosols at high mountain sites with complex weather conditions.
\end{abstract}

Keywords: air quality monitoring; low-cost sensors; evaluation and correction; random forest model; multiple linear regression model

\section{Introduction}

Air pollutants, such as fine particulate matter $\left(\mathrm{PM}_{2.5}\right)$, carbon monoxide $(\mathrm{CO})$, and ozone $\left(\mathrm{O}_{3}\right)$, are important components of the Earth's atmosphere and significantly affect the air quality, human 
health, and climate change [1-6]. In order to oversee the variations of air quality and release warnings in real time, major air pollutants have been monitored routinely by a variety of governments, as well as state and local regulatory agencies, by using sophisticated and expensive fixed-site instruments [7]. However, the number of air quality monitoring stations is largely limited by the cost of instruments and the availability of trained personnel to operate and maintain such instruments. Therefore, it is impractical to deploy intensive monitoring networks and gather air quality information at high spatial resolutions, especially in some undeveloped, remote, or high-elevation areas.

The development of low-cost and portable sensors provides a solid means to supply and extend the existing infrastructure, and increases the density and coverage of empirical measurements [8]. Generally, sensors that cost less than \$2000 to measure specific individual pollutants in the air are defined as low-cost sensors $[9,10]$. In recent years, air quality sensor networks have been established to improve current ambient air monitoring capabilities in many cities. For example, Hasenfratz et al. compiled a high-resolution urban air pollution map of Zurich, Switzerland, based on the data measured by sensors deployed on public transport vehicles [9]. Heimann et al. used a sensor network to quantify the contributions of regional and local sources to the air quality around the city of Cambridge, UK [10]. Schneider et al. utilized data fusion technology based on geostatistics to combine the sensors' data with an air pollution diffusion model to generate a detailed urban air quality map for Oslo, Norway [11].

Are the measurements of low-cost air quality sensors reliable? During the last decade, a number of researchers, entrepreneurs, and manufacturers have been devoted to developing these kinds of sensors and evaluating their performance under laboratory conditions [12-19]. For example, Wang et al. evaluated the performance of low-cost particle sensors and indicated the good ability of sensors to monitor particle concentrations with relatively high linearity and moderate repeatability [20]. Pang et al. investigated the influences of relative humidity $(\mathrm{RH})$ and gas sample flow rate on the sensor calibrations and sensitivities [21]. Meanwhile, the performance of sensors was also evaluated in the ambient atmosphere. Most of the previous studies focused on the influence of meteorological factors, such as temperature $(\mathrm{T}), \mathrm{RH}$, sunlight, and other factors, and proposed calibration schemes based on the long-term evaluation in urban and/or suburban environments [22-31]. In addition, some studies also paid attention to the influence of cross-sensitivities on sensors [12,32,33]. Many methods are used to calibrate air quality sensors, such as linear regression (LR), multi-linear regression (MLR), random forest (RF), artificial neural network (ANN), support vector machine (SVM), support vector regression (SVR), etc. [34]. LR and MLR use covariates to improve calibrations, and are the most popular methods used to calibrate the sensors' data. However, LR reports the worst $\mathrm{R}^{2}$ and should be avoided for gaseous sensors [35-37]. The remaining four calibration approaches are supervised learning techniques and can greatly improve the $\mathrm{R}^{2}$ in most sensors and situations. RF and ANN are two common supervised learning techniques but need a lot of data to train the models $[6,19,38,39]$. SVR and SVM are new machine learning methods based on statistical methods but are less commonly utilized. They approach the nonlinear function using control accuracy, and have the advantages of global optimization and good generalizability [40,41].

Despite the abovementioned great efforts in lab and ambient conditions at the ground level, the performance of low-cost air quality sensors has been not fully evaluated in high-elevation areas, where the meteorological conditions are quite different and usually more complicated than those at low elevations. Around the world, many cities are located in plateaus or mountainous areas, where sensors have a high potential to support the local and regional air quality monitoring. High mountain stations and research aircraft have proved to be useful sampling platforms for regional air pollution and atmospheric chemistry research [42,43]. However, it is much more difficult to monitor the air quality by using conventional methods (such as sophisticated and bulky instruments) at a mountain site or aboard an aircraft than on the ground. For example, only a few instruments can be carried up to the mountain top owing to the limitation of economy and personnel, and the instruments aboard an aircraft are weight limited. In addition, the meteorological conditions at high altitudes are more complicated than at low altitudes and are characterized by lower pressure, lower temperatures, and 
higher wind speeds, which are unfavorable for the instrument operation and make it easy to damage the instruments. Therefore, there is an urgent need to monitor air quality using low-cost sensors and to evaluate them based on commercial benchmark instruments in such harsh environments.

In this study, we conducted a long-term inter-comparison campaign with concurrent operation of both air quality monitoring sensors and commercial analyzers on the top of Mt. Tai (1534 m a.s.l.), which is located in the center of the North China Plain (NCP). The performance of several commonly used sensors was comprehensively evaluated, and the potential effects of meteorological parameters, such as T, RH, wind speed (WS), and atmospheric pressure on the sensor measurements were estimated. We demonstrate the capability of low-cost air quality sensors for the measurements of trace gases and aerosols in high-elevation areas and also propose optimization schemes to improve their measurement accuracy.

\section{Experiments}

\subsection{Site Description}

The field campaign was carried out at the summit of Mt. Tai $\left(36.16^{\circ} \mathrm{N}, 117.06^{\circ} \mathrm{E}, 1534 \mathrm{~m}\right.$ a.s.l., Figure 1) from 20 April to 30 November 2018. Mt. Tai is located in the center of the North China Plain and is the highest mountain in this region. The altitude of Mt. Tai places the study site in the transition region between the planetary boundary layer (PBL) and the free troposphere. During the daytime in summer, the summit of Mt. Tai reaches close to the top of the PBL, and the observations can represent the atmospheric environment at a regional scale. At nighttime, it is in the residual layer or free troposphere $[44,45]$. Thus, the site is suitable for studying the transport of atmospheric pollutants in Northeast Asia and the exchange of pollutants between the PBL and the free troposphere. The Mt. Tai station has been extensively deployed as a sampling platform in many previous studies, and the details of the study site can be found elsewhere [42,46,47].
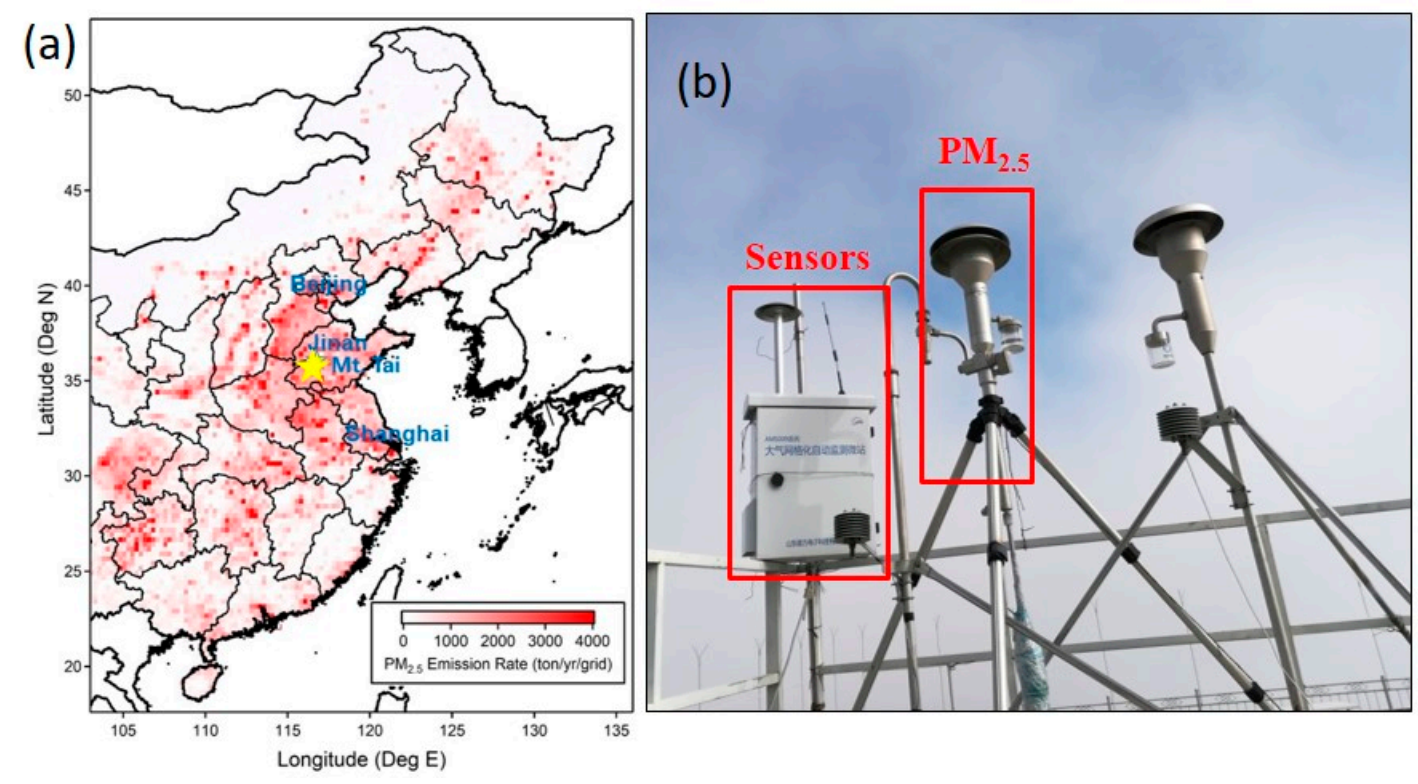

Figure 1. (a) Map showing the location of Mt. Tai. The emission data of fine particulate matter $\left(\mathrm{PM}_{2.5}\right)$ were downloaded from http://meicmodel.org/about.html. (b) Photo of the sampling inlets of the air quality sensor and benchmark instruments on the rooftop of Mt. Tai station. 


\subsection{Measurement Techniques}

The air quality monitoring sensors, integrated by Shandong Nova Fitness Co., Ltd. (Jinan, Shandong Province, China), were used and evaluated in the present study. The setup consisted of three sensors that respond to target species: CO (CF-200, http://www.membrapor.ch/sheet/CO-CF-200.pdf.), $\mathrm{O}_{3}$ (C-5, https://www.membrapor.ch/ sheet/O3-C-5.pdf) and $\mathrm{PM}_{2.5}$ (SDS019P, https://www-sd-nf.oss-cn-beijing.aliyuncs.com/官网下 载/SD019\%20Laser\%20PM2.5\%20Sensor\%20SpecificationV1.4.pdf). The technology of $\mathrm{O}_{3}$ and CO sensors is a three-electrode electrochemical system; it performs the redox reaction with the target gas and generates electrical signals proportional to the gas concentrations. As shown in Figure 2a, the electro-chemical sensors ( $\mathrm{CO}$ and $\mathrm{O}_{3}$ ) consist of a sensing electrode (or working electrode), a reverse electrode, and a reference electrode. The sensing electrode and the reverse electrode are separated by a thin electrolytic layer. The sample gas passes through the tiny capillary opening and hydrophobic barrier layer, finally reaching the electrode surface and reacting with the sensor electrode. The electronic device flows between the positive and negative electrodes through the resistor connected between the electrodes, and the electric current is proportional to the concentrations of the measured gas. In fact, the potential of the sensing electrode cannot remain constant due to the continuous electrochemical reaction on the surface of the electrode. Therefore, a reference electrode was introduced to avoid the degradation. Figure $2 \mathrm{~b}$ shows the schematic diagrams of the $\mathrm{PM}_{2.5}$ sensor. The theory is based on the laser diffraction method, i.e., particle density distribution is specified using the light intensity distribution patterns. The built-in algorithm can convert the particle density distribution into particle masses. There are four sub-sensors in the $\mathrm{PM}_{2.5}$ sensor, which are matched using meter timing. The output data are the average values of the four sub-sensors. If one sub-sensor is found to be abnormal by comparing with the other three sensors through the internal algorithm, it is eliminated, and the recorded $\mathrm{PM}_{2.5}$ data becomes the average of the three sub-sensors. The technical specifications of the air quality monitoring sensors are summarized in Table 1. All of the technologies of these three sensors have been verified and widely used in laboratories or at ground stations. It is also noteworthy that the air pressure at the summit of Mt. Tai is approximately $83.45-85.62 \mathrm{kPa}$, which is a little lower than the favorable pressure range as specified in Table 1 . The influence of the pressure on the sensors is detailed in Section 3. The time resolution of the three sensors was $30 \mathrm{~s}$. The sensors were calibrated by Shandong Nova Fitness Co., Ltd. (Jinan, Shandong Province, China). After installation, the sensors were no longer calibrated. During 20-23 August 2018, the power supply of the sensor was broken, and the data were lost.
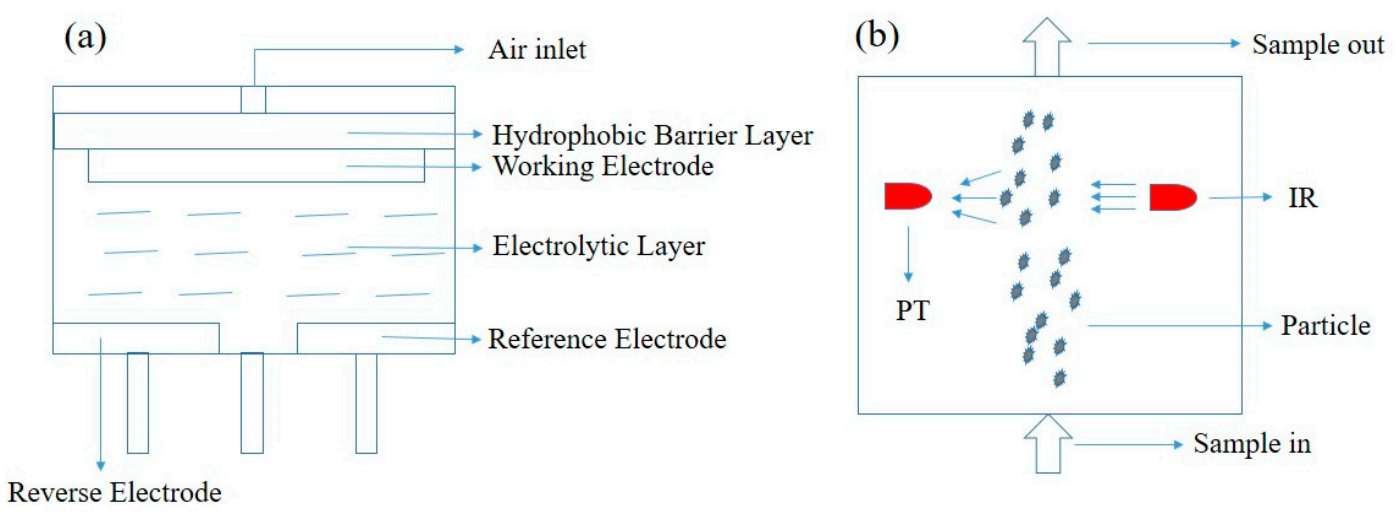

Figure 2. Schematic diagrams of the sensors evaluated in this work: (a) $\mathrm{CO}$ and $\mathrm{O}_{3}$, and (b) $\mathrm{PM}_{2.5}$. PT: Photodetector. 
Table 1. Technical specifications and applied environmental conditions of the low-cost air quality sensors.

\begin{tabular}{cccc}
\hline Parameter & $\mathbf{C O}(\mathbf{p p b})$ & $\mathbf{O}_{3}(\mathbf{p p b})$ & $\mathbf{P M}_{2.5}\left(\boldsymbol{\mu g} / \mathbf{m}^{\mathbf{3}}\right)$ \\
\hline Operation Principle & Three-electrode & Three-electrode & Laser scattering method \\
electrochemical & $0-5 \mathrm{ppm}$ & $0.0-1999.9 \mu \mathrm{g} / \mathrm{m}^{3}$ \\
Nominal Range & $0-200 \mathrm{ppm}$ & $<0.02 \mathrm{ppm}$ & $<10 \mu \mathrm{g} / \mathrm{m}^{3}$ \\
Resolution & $<0.1 \mathrm{ppm}$ & $<60 \mathrm{~s}$ & $1 \mathrm{~s}$ \\
Response Time & $<40 \mathrm{~s}$ & $0.1 \mathrm{ppm}$ & - \\
Maximum Zero Shift & $2 \mathrm{ppm}$ & $15 \%-90 \%$ & $0 \%-99 \%$ \\
Relative Humidity Range & $15 \%-90 \%$ & $-20{ }^{\circ} \mathrm{C}$ to $50{ }^{\circ} \mathrm{C}$ & $5{ }^{\circ} \mathrm{C}$ to $50^{\circ} \mathrm{C}$ \\
Temperature Range & $-20{ }^{\circ} \mathrm{C}$ to $50{ }^{\circ} \mathrm{C}$ & Atmospheric $\pm 10 \%$ & $86-110 \mathrm{kPa}$ \\
Pressure Range & Atmospheric $\pm 10 \%$ & 2 years in air & 3 years \\
Expected Operation Life & 3 years in air & &
\end{tabular}

At the Mt. Tai station, several trace gases (i.e., $\mathrm{O}_{3}, \mathrm{CO}, \mathrm{NO}, \mathrm{NO}_{2}$, and $\mathrm{NO}_{\mathrm{y}}$ ) and $\mathrm{PM}_{2.5}$ have been continuously measured since July 2017. In the present study, the concurrent data of $\mathrm{O}_{3}, \mathrm{CO}$, and $\mathrm{PM}_{2.5}$ were used to validate the sensor measurements. The commercial instruments were housed in a temperature-controlled container, and the ambient air was sampled through a Perfluoroalkoxy (PFA) tube with a total length of $2.3 \mathrm{~m}$ (1.3 m above the top of the container). As shown in Figure 1b, the sampling inlet for $\mathrm{PM}_{2.5}$ was adjacent to the sensors, and an automatic heating dehumidification system was deployed on the surface of the PFA tube to eliminate the influence of high RHs larger than $80 \%$. The gases' inlet was about $5 \mathrm{~m}$ from the sensors. The benchmark instruments used in this study were as follows: $\mathrm{CO}$ was measured using an infrared (IR) radiation analyzer (Teledyne Advanced Pollution Instrumentation (API), San Diego, California, USA) Model 300 was used from 20 April to 3 July 2018, and Model T300U was used from 4 July to 30 November 2018. The detection limit was $50 \mathrm{ppbv}$ for the former and $20 \mathrm{ppbv}$ for the latter. For these two analyzers, the time resolution was $1 \mathrm{~min}$ and the precision was $0.5 \% . \mathrm{O}_{3}$ was measured using an ultraviolet absorption analyzer (API Model T400, San Diego, California, USA). The detection limit was 0.4 ppbv, and the time resolution was $1 \mathrm{~min}$. The precision was $<0.5 \%$ of readings above $100 \mathrm{ppbv}$. The $\mathrm{PM}_{2.5}$ mass concentrations were measured using a SHARP 5030 (Thermo Fisher Scientific, Waltham, MA USA) via the light scattering and beta ray absorption method. The detection limit was $0.5 \mu \mathrm{g} / \mathrm{m}^{3}$, and the time resolution was $1 \mathrm{~min}$. The precision was $\pm 0.5 \%$. Meteorological data, including $\mathrm{T}, \mathrm{RH}, \mathrm{WS}$, and pressure, were obtained from the Mt. Tai meteorological station. These instruments have been widely applied in many previous studies, and the quality assurance and quality control protocols can be found elsewhere [46,48-50]. For $\mathrm{CO}$ and $\mathrm{O}_{3}$, we performed multi-point calibrations every month and changed the filter every two weeks. The calibration system consists of four parts: air pump (Jiangsu dynamic medical technology co.,ltd. Dynair DA5001/9, Suzhou, Jiangsu, China), Zero Air Supply (Thermo Fisher Scientific 111, Waltham, MA USA), Gas Dilution Calibrator (Sabio 4010, Round Rock, TX USA), and standard gas. The standard gas was produced by the National Institute of Metrology, China. $\mathrm{O}_{3}$ was calibrated using the NO titration method. $\mathrm{PM}_{2.5}$ was calibrated every three months using the method of mass foil calibration in the instrument manual.

\section{Inter-Comparison Results}

\subsection{Overview of the Measured Air Quality and Meteorological Conditions}

The measured meteorological conditions in the present study at Mt. Tai are documented in Figure 3 and Table 2. During the seven-month observation period, the ambient temperature varied from $10{ }^{\circ} \mathrm{C}$ to $25^{\circ} \mathrm{C}$ in the warm season (May to September) and from $-5{ }^{\circ} \mathrm{C}$ to $10{ }^{\circ} \mathrm{C}$ in the cold season (April and October to December). The RH varied from $10 \%$ to $100 \%$ and was higher than $67 \%$ during half of the time. The wind speed was greater than $5 \mathrm{~m} / \mathrm{s}$ most of the time, and the maximum instantaneous wind speed could reach $25 \mathrm{~m} / \mathrm{s}$. In addition, the atmospheric pressure varied from 
$83.45 \mathrm{kPa}$ to $85.62 \mathrm{kPa}$. Overall, the meteorological condition at Mt. Tai is characterized by a wide range of temperature, high $\mathrm{RH}$, and strong winds, which facilitates a thorough evaluation of the impacts of meteorological factors on sensor measurements.

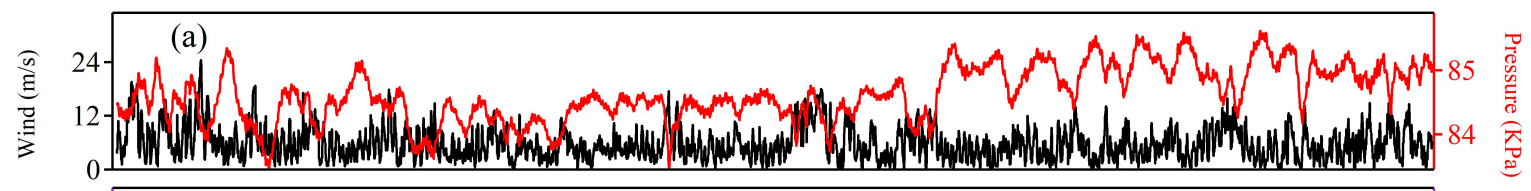

(b)
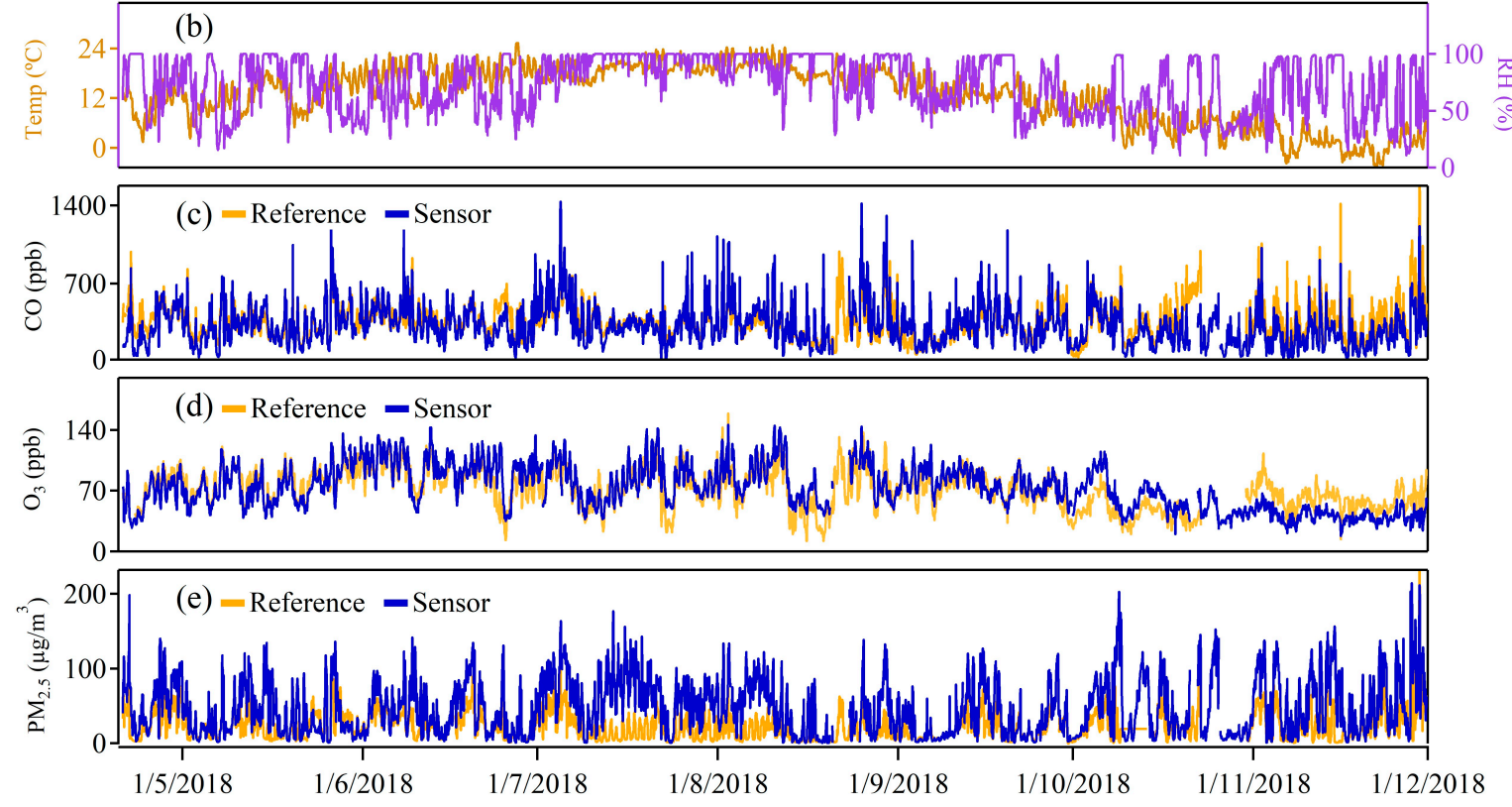

Figure 3. Time series of the measured metrological and air quality data at Mt. Tai from 20 April to 30 November 2018: (a) Wind speed (WS) and pressure, (b) temperature (T) and relative humidity (RH), (c) $\mathrm{CO},(\mathbf{d}) \mathrm{O}_{3}$, and (e) $\mathrm{PM}_{2.5}$.

Table 2. Statistics of the meteorological parameters and air pollutants measured by sensors and reference instruments at Mt. Tai during the inter-comparison campaign.

\begin{tabular}{cccccc}
\hline Species & Median & Average & Standard Deviation & Max & Min \\
\hline Wind Speed $(\mathrm{m} / \mathrm{s})$ & 5.1 & 5.8 & 3.6 & 24.5 & 0.0 \\
Temperature $\left({ }^{\circ} \mathrm{C}\right)$ & 14.0 & 12.6 & 24.2 & 100.0 & 10.7 \\
Relative Humidity $(\%)$ & 77.6 & 73.0 & 0.4 & 85.6 & 83.4 \\
Atmospheric Pressure $(\mathrm{kPa})$ & 84.6 & 84.6 & 179 & 1436 & 17 \\
$\mathrm{CO}(\mathrm{ppbv}$, sensor) & 299 & 324 & 164 & 1578 & 38 \\
$\mathrm{CO}(\mathrm{ppbv}$, reference) & 342 & 360 & 25 & 146 & 18 \\
$\mathrm{O}_{3}(\mathrm{ppbv}$, sensor) & 72 & 73 & 22 & 159 & 12 \\
$\mathrm{O}_{3}(\mathrm{ppbv}$, reference) & 72 & 72 & 36.7 & 214.5 & 0.4 \\
$\mathrm{PM}_{2.5}\left(\mu \mathrm{g} / \mathrm{m}^{3}\right.$, sensor) & 38.0 & 46.6 & 19.7 & 231.9 & 0.0 \\
$\mathrm{PM}_{2.5}\left(\mu \mathrm{g} / \mathrm{m}^{3}\right.$ reference) & 17.9 & 22.5 & & & \\
\hline
\end{tabular}

Table 2 also summarizes the measured air quality data at Mt. Tai from both the sensors and benchmark instruments. The high time resolution data were averaged to hourly concentrations for further analysis. The concentrations of CO measured by the sensor varied in the range of 17-1436 ppbv, with an average value ( \pm standard deviation) of $324 \pm 179 \mathrm{ppbv}$. In comparison, the reference analyzer derived a comparable average concentration of $360 \pm 164 \mathrm{ppbv}$ with a range of 38-1578 ppbv. For $\mathrm{O}_{3}$, the sensor measured concentrations that varied in the range of $18-146 \mathrm{ppbv}$, and the average value was $73 \pm 25 \mathrm{ppbv}$. The sensor measurements were highly consistent with the reference data, which varied 
in the range of $12-159 \mathrm{ppbv}$ and showed an average value of $72 \pm 23 \mathrm{ppbv}$. Furthermore, the average $\mathrm{O}_{3}$ concentration measured by the sensors and benchmark instruments during the warm season (May to September) was about $83 \pm 22 \mathrm{ppbv}$ and $78 \pm 22 \mathrm{ppbv}$, which was significantly higher than that in the cold season ( $52 \pm 18 \mathrm{ppbv}$ and $55 \pm 15 \mathrm{ppbv}$, April and October to November). It should be noticed that an $\mathrm{O}_{3}$ trough appeared in late August, which could be explained by the weak photochemistry reactions at high $\mathrm{RH}$ conditions. $\mathrm{PM}_{2.5}$ measured using sensors varied in the range of $0.4-214.5 \mu \mathrm{g} / \mathrm{m}^{3}$ with an average of $46.7 \pm 36.7 \mu \mathrm{g} / \mathrm{m}^{3}$. The mean of $\mathrm{PM}_{2.5}$ was much lower when measured using the benchmark instrument, i.e., $22.5 \pm 19.7 \mu \mathrm{g} / \mathrm{m}^{3}$, although the variation range of $0-231.9 \mu \mathrm{g} / \mathrm{m}^{3}$ was comparable to the sensor data. These measurement results indicate moderate air pollution at Mt. Tai and fairly good agreement between the sensors and reference analyzers. A detailed comparison is given in the following sections.

The difference between the sensors' data and the reference data is shown in Figure 4. For the raw $\mathrm{PM}_{2.5}$ data, the difference largely varied from $-62.9 \mu \mathrm{g} / \mathrm{m}^{3}$ to $200.4 \mu \mathrm{g} / \mathrm{m}^{3}$. The difference for raw $\mathrm{CO}$ and $\mathrm{O}_{3}$ was relatively stable, with occasional large deviations. We also added the difference between the corrected sensors' data (half a month) and reference data. The difference was close to 0 for the two methods, indicating that the two correction methods could improve the accuracy of the sensor measurements.
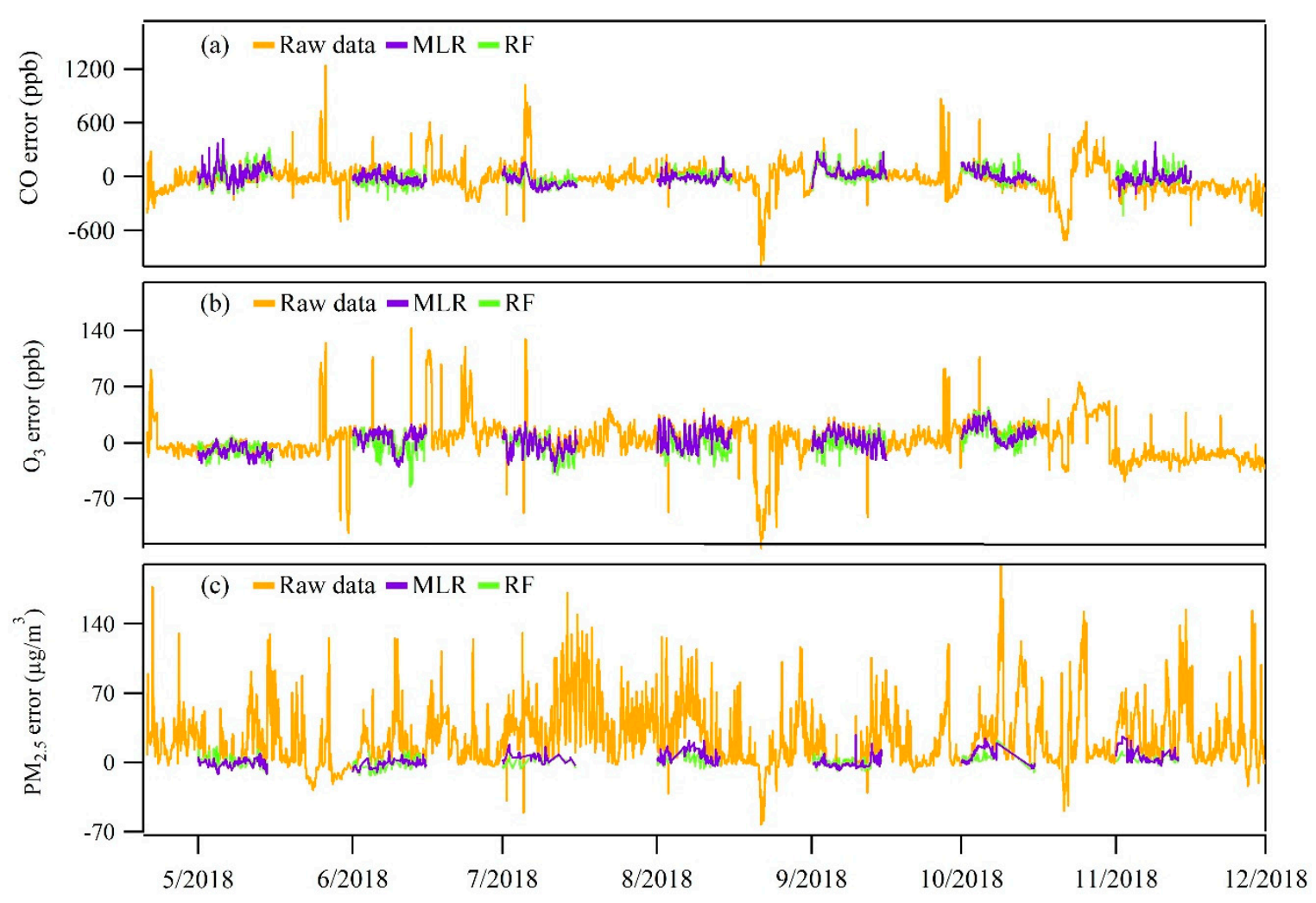

Figure 4. The difference between the sensors' data and the reference data, (a) $\mathrm{CO}$, (b) $\mathrm{O}_{3}$, and (c) $\mathrm{PM}_{2.5}$. MLR: multi-linear regression, RF: random forest.

\subsection{Inter-Comparison between Sensors and Reference Analyzers}

Figure 5 shows the scatter plots of the sensor data against the reference measurements over the whole experiment period. Strong positive linear relationships can be clearly seen for $\mathrm{CO}$ and $\mathrm{O}_{3}$, with the Pearson correlation coefficients $(r)$ of 0.83 and 0.79 , and reduced major axis (RMA) slopes of 0.92 and 0.89 , respectively. The RMA regression method was used here to eliminate the uncertainties of both variables [51]. Such results demonstrate the capability of low-cost air quality sensors to measure 
$\mathrm{CO}$ and $\mathrm{O}_{3}$ at high-elevation areas and under a variety of meteorological conditions, such as low temperature, low pressure, high $\mathrm{RH}$, and strong winds.
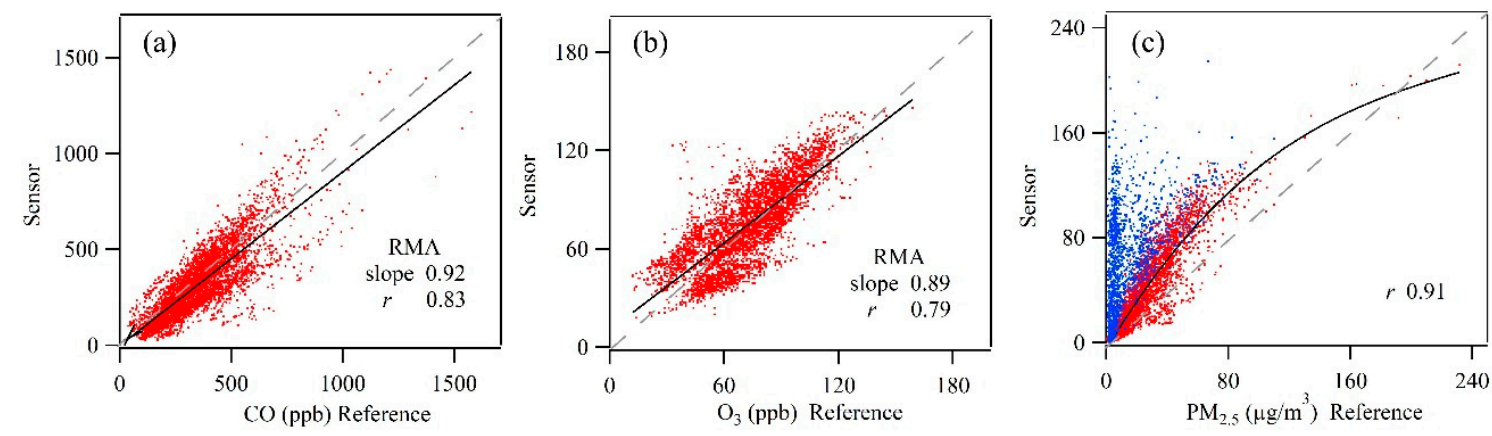

Figure 5. Scatter plots of (a) $\mathrm{CO},(\mathbf{b}) \mathrm{O}_{3}$, and (c) $\mathrm{PM}_{2.5}$ between low-cost air quality sensor and the benchmark instruments (blue dots were at $\mathrm{RH}>95 \%$ ). RMA: reduced major axis.

In Figure 5, the variation ranges of measurement data from the sensor and the reference analyzers were comparable, but the average value measured by the sensors was almost twice that of reference data (see Table 2). This was mainly because the sensor overestimated the $\mathrm{PM}_{2.5}$ under high $\mathrm{RH}$ conditions in July and August. During that period, ambient RH could reach $100 \%$ in nearly one third of the time. Figure $5 \mathrm{c}$ also shows that the $\mathrm{PM}_{2.5}$ sensor data were much higher than the reference data when the humidity was close to saturation (e.g., blue dots signify $\mathrm{RH}>95 \%$ ). This difference between the sensor and reference data should be due to the fact that $\mathrm{RH}$ can impose a significant effect on the $\mathrm{PM}_{2.5}$ measurements, and during the present study, the reference instrument had an automatic heating dehumidification system to eliminate the effects of high humidity, but the sensor did not have this system. We also removed the measurement data with $\mathrm{RH}>95 \%$ for further comparison to examine the responses of sensor performance to different $\mathrm{PM}_{2.5}$ pollution levels. From Figure $5 \mathrm{c}$ (see also Figure 6), a strong non-linear relationship could be fitted well between the sensor and reference data, with an $r$ value of 0.91 .

Some previous studies have suggested that the potential long-term baseline drift of air quality sensors may significantly interfere with the measurement results $[19,26,32]$. In this study, we also examined this issue by choosing the 5 -min resolution data in the cleanest conditions (i.e., $\mathrm{CO} \leq 150 \mathrm{ppbv}$, $\mathrm{O}_{3} \leq 40 \mathrm{ppbv}$, and $\mathrm{PM}_{2.5} \leq 10 \mu \mathrm{g} / \mathrm{m}^{3}$; note that all of these data were from the reference analyzers) to test the potential long-term drift of the sensors. During our observation period, no significant baseline drift was observed (figures not shown).

\subsection{Effect of Meteorological Factors on the Sensor Measurements}

As mentioned above, meteorological factors, such as temperature, relative humidity, wind speed, and atmospheric pressure, may influence the measurements of air quality sensors. Here, we further examined the effects of individual meteorological factors on the three sensors by using the observations of reference analyzers as benchmarks. Figure 6 shows the scatter plots of the sensor data and reference data color-coded with the meteorological factors. Note that the sensor data of $\mathrm{PM}_{2.5}$ measured when RH $>95 \%$ were excluded here. Overall, each meteorological factor showed different effects on the different sensors. For example, the $\mathrm{CO}$ and $\mathrm{O}_{3}$ values measured by sensors were lower than those of reference analyzers at low temperature, but as the temperature increased, the $\mathrm{CO}$ and $\mathrm{O}_{3}$ values measured by sensors tended to be larger than the reference data (Figure $6 a, b)$, suggesting the positive interference of increasing temperature with the sensor observations. Therefore, the ratio of sensor data to reference data (sensor/reference) was used to evaluate the influence of meteorological factors on the sensors' performance (see Figure 7). 

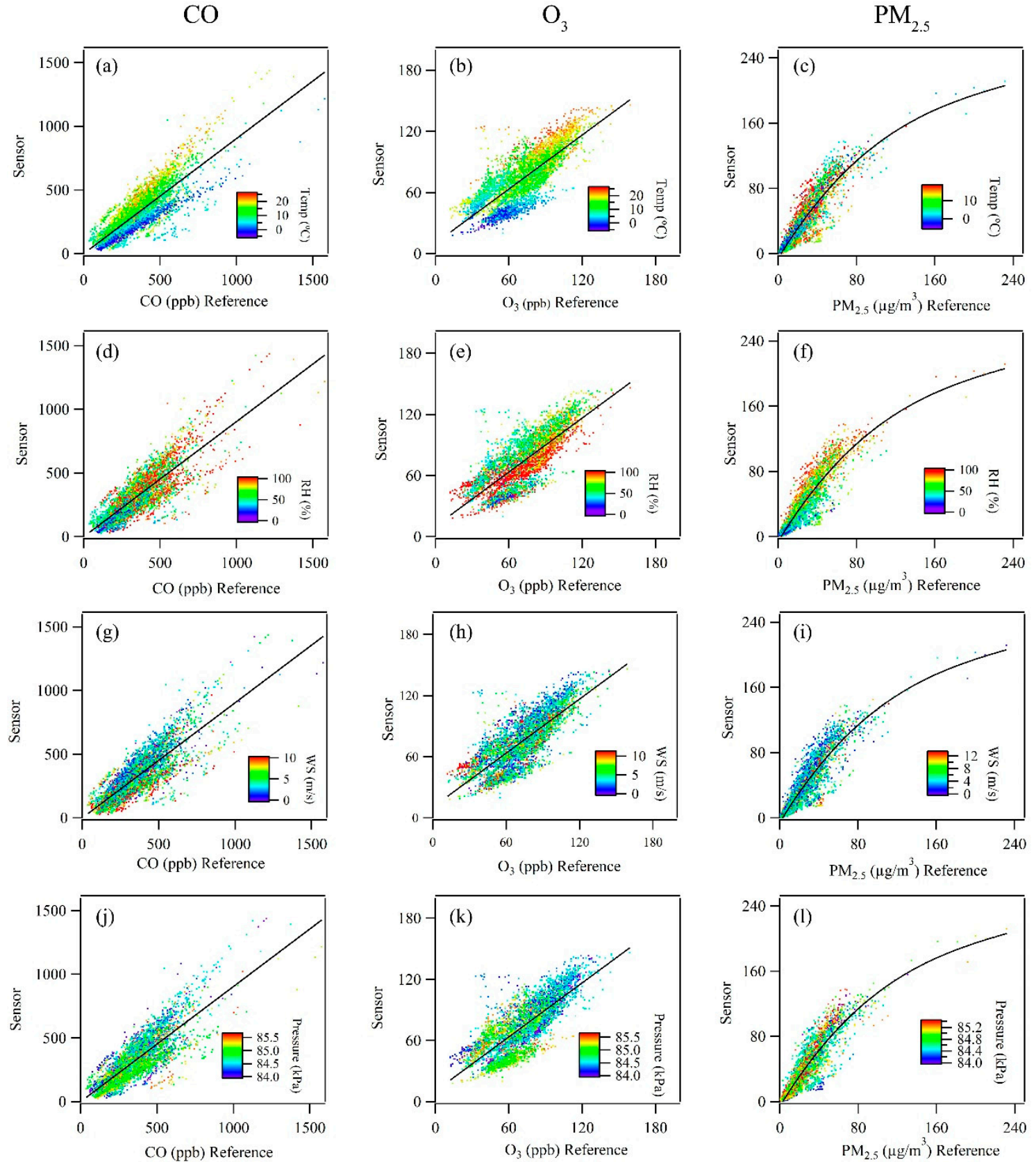

Figure 6. Scatter plots of sensor data and reference data, color-coded with meteorological factors: $(\mathbf{a}-\mathbf{c})$ temperature, $(\mathbf{d}-\mathbf{f})$ relative humidity, $(\mathbf{g}-\mathbf{i})$ wind speed, and $(\mathbf{j}-\mathbf{l})$ pressure. 

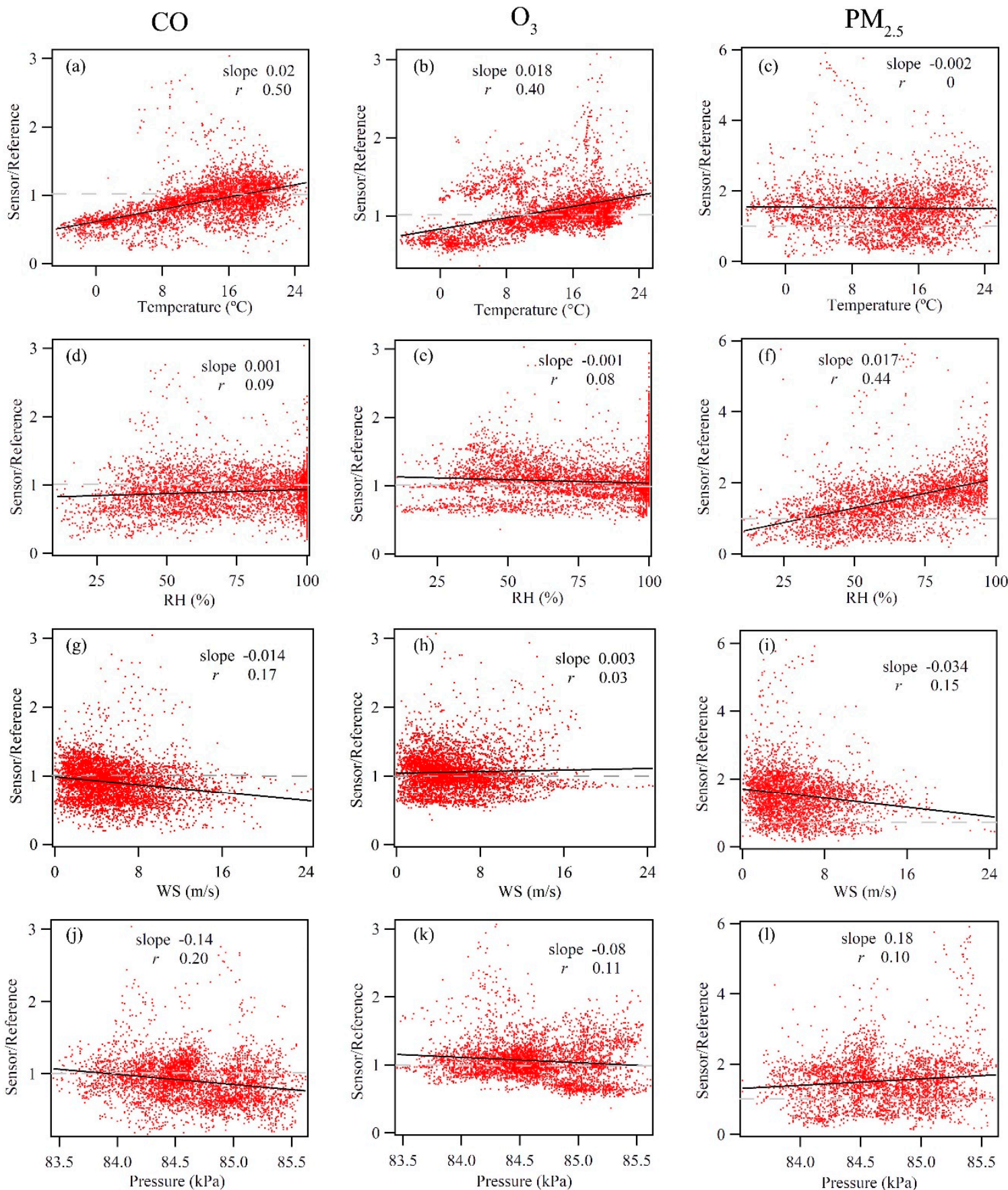

Figure 7. Scatter plots of sensor/reference ratios against meteorological factors: $(\mathbf{a}-\mathbf{c})$ temperature, $(\mathbf{d}-\mathbf{f})$ relative humidity, $(\mathbf{g}-\mathbf{i})$ wind speed, and $(\mathbf{j}-\mathbf{l})$ pressure.

Temperature: Figure 7a-c show the influence of temperature on the three sensors. For $\mathrm{CO}$ and $\mathrm{O}_{3}$, the sensor/reference ratio showed an obvious increasing trend with the increase of air temperature $(r=0.5$ and 0.4), indicating the positive effect of temperature on the two gas sensors (Figure 7a,b). Based on the regression equation, the $\mathrm{CO}$ and $\mathrm{O}_{3}$ sensors showed the best performance at temperatures around $17^{\circ} \mathrm{C}$ and $9^{\circ} \mathrm{C}$, which was when the sensor/reference ratios were close to 1 . However, these dots were dispersed and partly coincided with the baseline (sensor/reference equal to 1 ) between $8-23^{\circ} \mathrm{C}$ for $\mathrm{CO}$ and between $8-22{ }^{\circ} \mathrm{C}$ for $\mathrm{O}_{3}$. Otherwise, the sensors may overestimate (underestimate) at higher (lower) temperatures compared to the reference analyzers. For $\mathrm{PM}_{2.5}$, the ratios of sensor/reference were relatively scattered with an average value of $1.5 \pm 0.8$ and showed little correlation with temperature, 
suggesting that temperature may have no impact on the $\mathrm{PM}_{2.5}$ sensor (Figure 7c). The positive effect of temperature on the measurements of $\mathrm{O}_{3}$ and $\mathrm{CO}$ sensors could be explained by the unstable transformation velocity, i.e., air temperature influenced the transformation velocity of $\mathrm{CO}$ and $\mathrm{O}_{3}$ gases passing through the hydrophobic barrier layer and changed the migration rate of ions and electrons in the electrolyte and the rate of redox reaction, resulting in errors in the sensor measurements.

Relative Humidity: For the two gaseous species of $\mathrm{CO}$ and $\mathrm{O}_{3}$, the sensor/reference ratios in different RH bins were around 1 , and the correlations with RH were quite weak $(r=0.09$ and 0.08$)$, indicating that $\mathrm{RH}$ may have had little effect on the $\mathrm{CO}$ and $\mathrm{O}_{3}$ sensors (Figure $7 \mathrm{~d}, \mathrm{e}$ ). For the $\mathrm{PM}_{2.5}$ sensor data, in comparison, a moderate positive effect of RH could be clearly illustrated (Figure 7f). The $r$ value of the linear regression of the sensor/reference ratios with RH was 0.44 . Based on the regression equation, we inferred that the ratio of sensor/reference was close to 1 when RH was around $32 \%$. Considering the dispersed scatters, these dots partly coincided with the baseline when the RH was below $65 \%$. In other words, the particle mass sensor may have largely overestimated the $\mathrm{PM}_{2.5}$ concentrations when $\mathrm{RH}$ was larger than $65 \%$. According to the working principle of the $\mathrm{PM}_{2.5}$ sensor, we inferred that water vapor could absorb part of the light under high RH conditions. Then, the light intensity received by the photoelectric transistors was reduced, leading to an overestimation of particle mass concentrations.

Wind Speed: As shown in Figure 7g,i, increasing wind speed showed a weak negative effect on the $\mathrm{CO}$ and $\mathrm{PM}_{2.5}$ sensors. The $\mathrm{CO}$ sensor showed the best performance when the wind speed was close to $0 \mathrm{~m} / \mathrm{s}$ and tended to underestimate $\mathrm{CO}$ under high WSs. For the $\mathrm{PM}_{2.5}$, the ratios of sensor/reference were larger than 1 , indicating the overestimation of the $\mathrm{PM}_{2.5}$ sensor. For $\mathrm{O}_{3}$, the sensor/reference ratios for different wind speed bins were around 1 , and the correlations with wind speed were quite weak $(r=0.03)$, indicating that wind speed had little effect on the $\mathrm{O}_{3}$ sensor (Figure $7 \mathrm{~h}$ ). Considering the cost of the sensors, the manufacturer designed the fan rotation for the sampling of ambient air. We speculate that the amount of air entering the instrument changed with the dramatic change of atmospheric pressure caused by changes in the wind speed. For example, when the wind speed was large, less air could enter the sensor and participate in the reaction. Thus, higher wind speed may have a negative impact on sensor measurements.

Atmospheric Pressure: During our observations, the atmospheric pressure varied in a narrow range of $83.45-85.62 \mathrm{kPa}$. The air pressure showed a weak negative effect on the $\mathrm{CO}$ sensor, which showed the best performance when the pressure was close to $83.95 \mathrm{kPa}$ (Figure 7j). As shown in Figure 7k-1, air pressure did not show obvious correlations with the sensor/reference ratios for the $\mathrm{O}_{3}$ and $\mathrm{PM}_{2.5}$ sensors, implying the negligible effects of air pressure on $\mathrm{O}_{3}$ and $\mathrm{PM}_{2.5}$ sensor measurements. The sensor/reference ratios of $\mathrm{CO}, \mathrm{O}_{3}$, and $\mathrm{PM}_{2.5}$ were all around unity for different pressure bins, with average values of $0.90 \pm 0.30,1.06 \pm 0.31$, and $1.53 \pm 0.79$, respectively. It is worth noting that the air pressure at Mt. Tai was slightly out of range of the favorable operating pressure specified by the manufacturers. Our results suggest that the air quality sensors may work reasonably well under low pressure conditions in high-elevation areas, such as Mt. Tai.

\section{Correction of the Sensor Measurement Data}

As discussed above, the sensor measurement data may be significantly interfered with by the meteorological conditions. It is thus crucial to correct the sensor measurement data with the in situ meteorological parameters such that the data are consistent and inter-comparable. In the present study, two data correction methods were developed and tested, i.e., the MLR and RF models. This study lasted for seven months and covered multiple seasons and a wide range of meteorological conditions, and thus provided a good opportunity for the development, training, and validation of these two numerical models.

The MLR model developed the multiple linear regressions of the reference data as a function of the sensor measurement data; the slope between the sensor data and the reference data; and various meteorological parameters including temperature, $\mathrm{RH}$, wind speed, and pressure. The MLR model 
can be represented using Equation (1), where $x$ and $y$ denote the measurement data obtained from the sensor and reference analyzers; $a$ and $b$ are the slope and intercept between the sensor data and reference data and $\beta 1, \beta 2$, and $\beta 3$ are the correlation coefficients with individual variables. The model was performed using the least squares approach.

$$
\mathrm{y}=[x(1+\beta 1 \times T+\beta 2 \times R H+\beta 3 \times W S)-b] \times a
$$

The RF model, a machine learning algorithm belonging to the ensemble based classifiers, is used for solving regression or classification problems [39,52]. As the name implies, the RF model is a forest established in a random way. There are many decision trees in the forest, and they have no correlation with each other. When a new input sample enters after obtaining the forest, each decision tree in the forest analyzes and gives the relationship between various factors in the sample. Then the final data calibration model is calculated as a (voted or averaged) sum of individual relationship. The RF model can reduce the variance of the prediction by merging the prediction results of each tree and improve the performance on the test set [53]. For example, we randomly chose 1000 datasets (including reference instrument data $(y)$, sensor data $(x 1)$, and meteorological data $\left.\left(x_{2}\right)\right)$ as training data and put them into the model. First, the RF model randomly assigned these data to form $n$ groups of data packets ( $n$ could be hundreds or thousands). Second, data packets were used to train a decision tree and find the algorithm according to every data packet. Finally, the model used the algorithms to correct the test data (sensor data $(x 1)$ and meteorological data $(x 2))$, and they were then further analyzed and sorted to find the best $t$ output data. In the present study, the RF model used the sensor measurement data, temperature, RH, WS, and pressure data to predict the actual pollutant concentrations, which could be compared against the reference measurement data. The $n$ was set to 500 in our RF model, and our collocation window covered a broad range of concentrations and meteorological conditions. During data preprocessing via the random forest model, missing data were deleted from the original data set [38].

In the present study, we used half of the collected data (15 days in each month) to develop the MLR model and RF model, and the rest of the data were used to validate the developed models. For CO and $\mathrm{O}_{3}$, we used the whole dataset to develop and validate the models. However, the high-concentration $\mathrm{PM}_{2.5}$ data rarely appeared, but the RF model needed huge quantities of data to be developed. Thus, we only used the $\mathrm{PM}_{2.5}$ data that was less than $36.8 \mu \mathrm{g} / \mathrm{m}^{3}$ (accounting for $80 \%$ of the whole dataset) to develop and validate the two models.

The comparison between the corrected data and reference data is shown in Figure 8. The RMA slopes of the raw data were $0.82,0.85$, and 1.36 for $\mathrm{CO}, \mathrm{O}_{3}$, and $\mathrm{PM}_{2.5}$, respectively (Figure $8 \mathrm{a}, \mathrm{d}, \mathrm{g}$ ). After correction, the slopes were 0.88, 0.95, and 0.97 in the MLR model and 0.90, 0.89, 0.88 in the RF model. Our result shows that the MLR model had a better performance when correcting the sensor measurement data, especially for $\mathrm{O}_{3}$ and $\mathrm{PM}_{2.5}$. Neither method was good for $\mathrm{CO}$ correction, suggesting other factors also influenced the $\mathrm{CO}$ sensor. In addition, the $r$ was slightly improved to 0.86- 0.88 using the two models. Note that both of the methods failed to correct the $\mathrm{PM}_{2.5}$ sensor data under RHs larger than 95\%. Overall, the MLR model showed a better performance than the RF model, since it could improve the RMA slope to be closer to 1 . The unsatisfactory result of the RF model was because it required huge quantities of data (preferably covering all probabilities) to develop the model. 


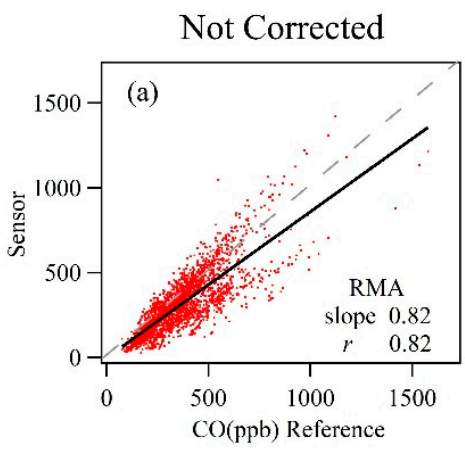

Multiple Linear Regression
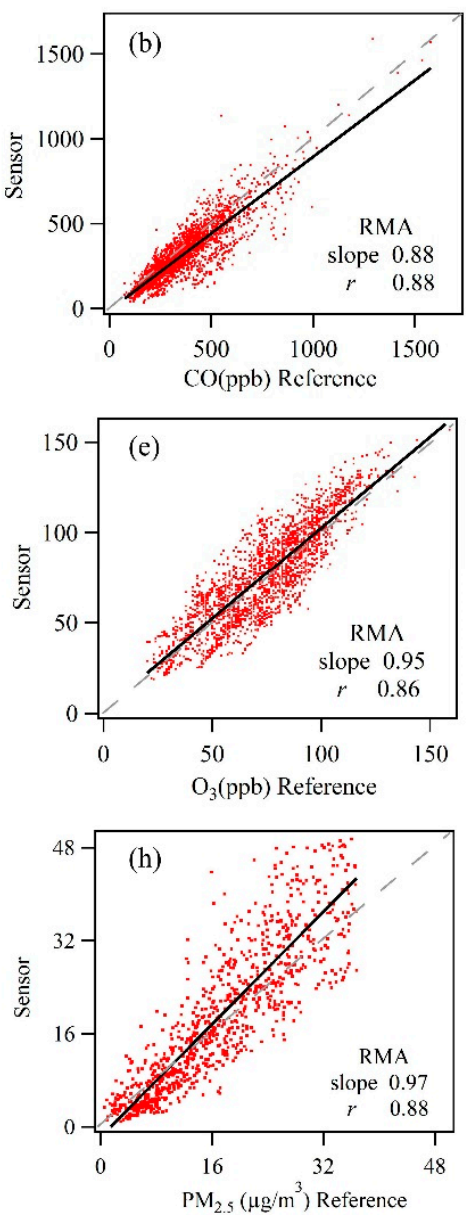

Random Forest
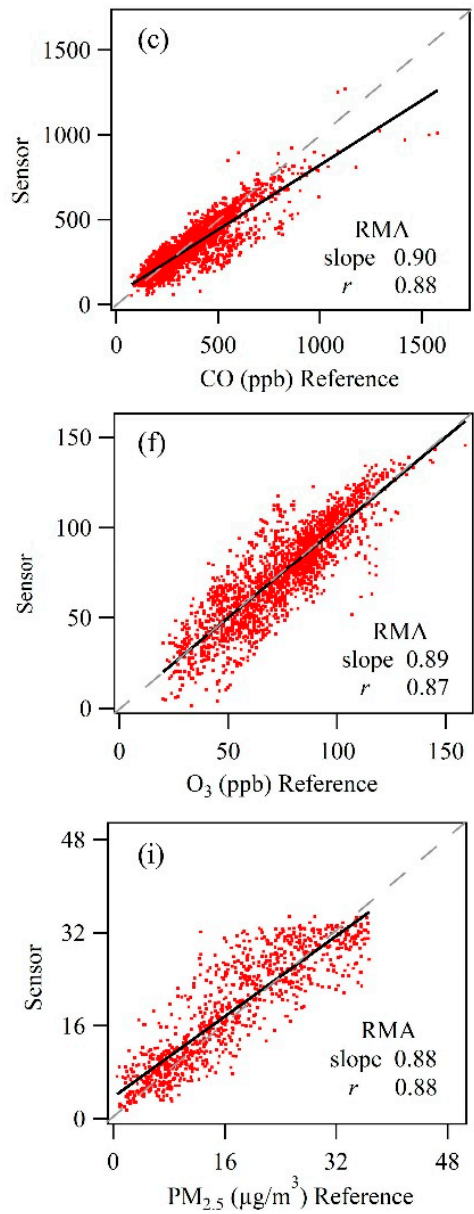

Figure 8. Comparison of scatterplots between the reference and sensor data for the test dataset of the original out-of-sensor data $(\mathbf{a}, \mathbf{d}, \mathbf{g})$, after correction using multiple linear regression $(\mathbf{b}, \mathbf{e}, \mathbf{h})$, and after correction using a random forest model $(\mathbf{c}, \mathbf{f}, \mathbf{i})$.

\section{Conclusions}

We thoroughly evaluated the performance of three air quality monitoring sensors at a high mountain site with harsh environmental conditions. During our observations, the three low-cost air quality sensors generally performed well, although some of the environmental conditions were out of the recommended specifications. For example, the atmospheric pressure was lower than the recommended specifications for the sensors, but the three sensors could still work reasonably well. The $\mathrm{RH}$ required for the $\mathrm{CO}$ and $\mathrm{O}_{3}$ sensors was $15 \%-90 \%$, but the two sensors could still work well when $\mathrm{RH}$ was out of this range. The exception was that the $\mathrm{PM}_{2.5}$ sensor could not work well when RH exceeded $95 \%$. Our study also suggested that the working conditions in the manual should be modified for high mountain environments.

Overall, our study suggests that air quality sensors can be used to monitor the trace gases and aerosols at high mountain sites, and thus enhance the monitoring capability due to their low cost and easy operation. Here, we also propose some optimization schemes to improve the performance of the sensor measurements: (1) an internal temperature compensation (fourth electrode) should be adopted to remove the influence of temperature; (2) an automatic dehumidifier should be equipped to eliminate the effects of high $\mathrm{RH}$, especially for the $\mathrm{PM}_{2.5}$ sensor; (3) a mass flowmeter or voltage regulator should be adopted to ensure the steady flow of gas through the sensor and prevent atmospheric pressure and wind speed fluctuations; and (4) a built-in chemical filter or a more suitable electrochemical working 
fluid should be added to eliminate the cross interference from other gases. These improvements will also certainly increase the cost of the sensors. Therefore, the data quality and sensor cost need to be well balanced.

Author Contributions: Conceptualization, H.L. and L.X.; methodology, H.L., Y.Z. (Yujiao Zhu), and L.X.; formal analysis, T.C.; investigation, Y.Z. (Yong Zhao), Y.J., Y.S., Y.L., and J.M.; data curation, X.Y., D.W., C.Z., and S.S.; writing-original draft preparation, H.L.; writing—review and editing, Y.Z. (Yujiao Zhu) and L.X.; project administration, X.W., W.W., and L.X.; funding acquisition, L.X. All authors have read and agreed to the published version of the manuscript.

Funding: This work was funded by the National Key Research and Development Program of China (no. 2016YFC0200500), the Qilu Youth Talent Program of Shandong University, and the Jiangsu Collaborative Innovation Center for Climate Change.

Acknowledgments: The authors thank Yiping Liu and Shitian Cou for their help in the maintenance and operation of the air quality monitoring sensors. We also appreciate all of the staff of the Taishan National Reference Climatological Station for aiding with the logistics and providing help during the field work.

Conflicts of Interest: The authors declare no conflict of interest.

\section{References}

1. Chameides, W.L.; Yu, H.; Liu, S.C.; Bergin, M.; Zhou, X.; Mearns, L.; Wang, G.; Kiang, C.S.; Saylor, R.D.; Luo, C. Case Study of the Effects of Atmospheric Aerosols and Regional Haze on Agriculture: An Opportunity to Enhance Crop Yields in China through Emission Controls? Proc. Natl. Acad. Sci. USA 1999, 96, 13626-13633. [CrossRef] [PubMed]

2. Chameides, W.L.; Xingsheng, L.; Xiaoyan, T.; Xiuji, Z.; Luo, C.; Kiang, C.S.; St John, J.; Saylor, R.D.; Liu, S.C.; Lam, K.S.; et al. Is ozone pollution affecting crop yields in China? Geophys. Res. Lett. 1999, 26, 867-870. [CrossRef]

3. Weichenthal, S.; Kulka, R.; Dubeau, A.; Martin, C.; Wang, D.; Dales, R. Traffic-Related Air Pollution and Acute Changes in Heart Rate Variability and Respiratory Function in Urban Cyclists. Environ. Health Perspect. 2011, 119, 1373-1378. [CrossRef] [PubMed]

4. Allen, R.J.; Sherwood, S.C.; Norris, J.R.; Zender, C.S. Recent Northern Hemisphere tropical expansion primarily driven by black carbon and tropospheric ozone. Nature 2012, 485, U350-U393. [CrossRef] [PubMed]

5. Heck, J.E.; Wu, J.; Lombardi, C.; Qiu, J.H.; Meyers, T.J.; Wilhelm, M.; Cockburn, M.; Ritz, B. Childhood Cancer and Traffic-Related Air Pollution Exposure in Pregnancy and Early Life. Environ. Health Perspect. 2013, 121, 1385-1391. [CrossRef] [PubMed]

6. Liu, H.Y.; Schneider, P.; Haugen, R.; Vogt, M. Performance Assessment of a Low-Cost PM2.5 Sensor for a near Four-Month Period in Oslo, Norway. Atmosphere 2019, 10, 18. [CrossRef]

7. Snyder, E.G.; Watkins, T.H.; Solomon, P.A.; Thoma, E.D.; Williams, R.W.; Hagler, G.S.W.; Shelow, D.; Hindin, D.A.; Kilaru, V.J.; Preuss, P.W. The Changing Paradigm of Air Pollution Monitoring. Environ. Sci. Technol. 2013, 47, 11369-11377. [CrossRef]

8. Holstius, D.M.; Pillarisetti, A.; Smith, K.R.; Seto, E. Field calibrations of a low-cost aerosol sensor at a regulatory monitoring site in California. Atmos. Meas. Tech. 2014, 7, 1121-1131. [CrossRef]

9. Sousan, S.; Koehler, K.; Hallett, L.; Peters, T.M. Evaluation of the Alphasense optical particle counter (OPC-N2) and the Grimm portable aerosol spectrometer (PAS-1.108). Aerosol Sci. Technol. 2016, 50, 1352-1365. [CrossRef]

10. Cross, E.S.; Williams, L.R.; Lewis, D.K.; Magoon, G.R.; Onasch, T.B.; Kaminsky, M.L.; Worsnop, D.R.; Jayne, J.T. Use of electrochemical sensors for measurement of air pollution: Correcting interference response and validating measurements. Atmos. Meas. Tech. 2017, 10, 3575-3588. [CrossRef]

11. Hasenfratz, D.; Saukh, O.; Walser, C.; Hueglin, C.; Fierz, M.; Arn, T.; Beutel, J.; Thiele, L. Deriving high-resolution urban air pollution maps using mobile sensor nodes. Pervasive Mob. Comput. 2015, 16, 268-285. [CrossRef]

12. Heimann, I.; Bright, V.B.; McLeod, M.W.; Mead, M.I.; Popoola, O.A.M.; Stewart, G.B.; Jones, R.L. Source attribution of air pollution by spatial scale separation using high spatial density networks of low cost air quality sensors. Atmos. Environ. 2015, 113, 10-19. [CrossRef] 
13. Schneider, P.; Castell, N.; Vogt, M.; Dauge, F.R.; Lahoz, W.A.; Bartonova, A. Mapping urban air quality in near real-time using observations from low-cost sensors and model information. Environ. Int. 2017, 106, 234-247. [CrossRef] [PubMed]

14. Austin, C.C.; Roberge, B.; Goyer, N. Cross-sensitivities of electrochemical detectors used to monitor worker exposures to airborne contaminants: False positive responses in the absence of target analytes. J. Environ. Monit. 2006, 8, 161-166. [CrossRef] [PubMed]

15. Peters, T.M.; Ott, D.; O'Shaughnessy, P.T. Comparison of the Grimm 1.108 and 1.109 portable aerosol spectrometer to the TSI 3321 aerodynamic particle sizer for dry particles. Ann. Occup. Hyg. 2006, 50, 843-850. [CrossRef] [PubMed]

16. Austin, E.; Novosselov, I.; Seto, E.; Yost, M.G. Laboratory Evaluation of the Shinyei PPD42NS Low-Cost Particulate Matter Sensor. PLoS ONE 2015, 10, 2. [CrossRef]

17. Liu, D.; Zhang, Q.; Jiang, J.K.; Chen, D.R. Performance calibration of low-cost and portable particular matter (PM) sensors. J. Aerosol. Sci. 2017, 112, 1-10. [CrossRef]

18. Papapostolou, V.; Zhang, H.; Feenstra, B.J.; Polidori, A. Development of an environmental chamber for evaluating the performance of low-cost air quality sensors under controlled conditions. Atmos. Environ. 2017, 171, 82-90. [CrossRef]

19. Pang, X.B.; Shaw, M.D.; Gillot, S.; Lewis, A.C. The impacts of water vapour and co-pollutants on the performance of electrochemical gas sensors used for air quality monitoring. Sens. Actuator B-Chem. 2018, 266, 674-684. [CrossRef]

20. Wei, P.; Ning, Z.; Ye, S.; Sun, L.; Yang, F.H.; Wong, K.C.; Westerdahl, D.; Louie, P.K.K. Impact Analysis of Temperature and Humidity Conditions on Electrochemical Sensor Response in Ambient Air Quality Monitoring. Sensors 2018, 18, 16. [CrossRef]

21. Wang, Y.; Li, J.Y.; Jing, H.; Zhang, Q.; Jiang, J.K.; Biswas, P. Laboratory Evaluation and Calibration of Three Low- Cost Particle Sensors for Particulate Matter Measurement. Aerosol Sci. Technol. 2015, 49, $1063-1077$. [CrossRef]

22. Pang, X.B.; Shaw, M.D.; Lewis, A.C.; Carpenter, L.J.; Batchellier, T. Electrochemical ozone sensors: A miniaturised alternative for ozone measurements in laboratory experiments and air-quality monitoring. Sens. Actuator B-Chem. 2017, 240, 829-837. [CrossRef]

23. Chakrabarti, B.; Fine, P.M.; Delfino, R.; Sioutas, C. Performance evaluation of the active-flow personal DataRAM PM2.5 mass monitor (Thermo Anderson pDR-1200) designed for continuous personal exposure measurements. Atmos. Environ. 2004, 38, 3329-3340. [CrossRef]

24. Spinelle, L.; Gerboles, M.; Villani, M.G.; Aleixandre, M.; Bonavitacola, F. Field calibration of a cluster of low-cost commercially available sensors for air quality monitoring. Part B: $\mathrm{NO}, \mathrm{CO}$ and $\mathrm{CO}_{2}$. Sens. Actuator B-Chem. 2017, 238, 706-715. [CrossRef]

25. Spinelle, L.; Gerboles, M.; Villani, M.G.; Aleixandre, M.; Bonavitacola, F. Field calibration of a cluster of low-cost available sensors for air quality monitoring. Part A: Ozone and nitrogen dioxide. Sens. Actuator B-Chem. 2015, 215, 249-257. [CrossRef]

26. Lin, C.; Gillespie, J.; Schuder, M.D.; Duberstein, W.; Beverland, I.J.; Heal, M.R. Evaluation and calibration of Aeroqual series 500 portable gas sensors for accurate measurement of ambient ozone and nitrogen dioxide. Atmos. Environ. 2015, 100, 111-116. [CrossRef]

27. Masson, N.; Piedrahita, R.; Hannigan, M. Quantification Method for Electrolytic Sensors in Long-Term Monitoring of Ambient Air Quality. Sensors 2015, 15, 27283-27302. [CrossRef]

28. Popoola, O.A.M.; Stewart, G.B.; Mead, M.I.; Jones, R.L. Development of a baseline-temperature correction methodology for electrochemical sensors and its implications for long-term stability. Atmos. Environ. 2016, 147, 330-343. [CrossRef]

29. Jiao, W.; Hagler, G.; Williams, R.; Sharpe, R.; Brown, R.; Garver, D.; Judge, R.; Caudill, M.; Rickard, J.; Davis, M.; et al. Community Air Sensor Network (CAIRSENSE) project: Evaluation of low-cost sensor performance in a suburban environment in the southeastern United States. Atmos. Meas. Tech. 2016, 9, 5281-5292. [CrossRef]

30. Rogulski, M. Low-cost PM monitors as an opportunity to increase the spatiotemporal resolution of measurements of air quality. In International Scientific Conference-Environmental and Climate Technologies; Valtere, S., Ed.; Elsevier Science Bv: Amsterdam, The Netherlands, 2017; Volume 128, pp. 437-444. 
31. Zheng, T.S.; Bergin, M.H.; Johnson, K.K.; Tripathi, S.N.; Shirodkar, S.; Landis, M.S.; Sutaria, R.; Carlson, D.E. Field evaluation of low-cost particulate matter sensors in high-and low-concentration environments. Atmos. Meas. Tech. 2018, 11, 4823-4846. [CrossRef]

32. Mead, M.I.; Popoola, O.A.M.; Stewart, G.B.; Landshoff, P.; Calleja, M.; Hayes, M.; Baldovi, J.J.; McLeod, M.W.; Hodgson, T.F.; Dicks, J.; et al. The use of electrochemical sensors for monitoring urban air quality in low-cost, high-density networks. Atmos. Environ. 2013, 70, 186-203. [CrossRef]

33. Lewis, A.C.; Lee, J.D.; Edwards, P.M.; Shaw, M.D.; Evans, M.J.; Moller, S.J.; Smith, K.R.; Buckley, J.W.; Ellis, M.; Gillot, S.R.; et al. Evaluating the performance of low cost chemical sensors for air pollution research. Faraday Discuss. 2016, 189, 85-103. [CrossRef] [PubMed]

34. Karagulian, F.; Gerboles, M.; Barbiere, M.; Kotsev, A.; Lagler, F.; Borowiak, A. Review of Sensors for Air Quality Monitoring; Joint Research Centre: Ispra, Italy, 2019.

35. Alejandro, V.; Renato, F.; Filippo, G.; Bartolomeo, M.; Maurizio, R. A Mobile and Low-Cost System for Environmental Monitoring: A Case Study. Sensors 2016, 16, 710.

36. Shao, W.; Zhang, H.; Zhou, H. Fine Particle Sensor Based on Multi-Angle Light Scattering and Data Fusion. Sensors 2017, 17, 1033. [CrossRef] [PubMed]

37. Cavaliere, A.; Carotenuto, F.; Di Gennaro, F.; Gioli, B.; Gualtieri, G.; Martelli, F.; Matese, A.; Toscano, P.; Vagnoli, C.; Zaldei, A. Development of Low-Cost Air Quality Stations for Next Generation Monitoring Networks: Calibration and Validation of PM2.5 and PM10 Sensors. Sensors 2018, 18, 2843. [CrossRef] [PubMed]

38. Wang, Y.W.; Du, Y.J.; Wang, J.N.; Li, T.T. Calibration of a low-cost PM2.5 monitor using a random forest model. Environ. Int. 2019, 133, 5. [CrossRef]

39. Borrego, C.; Ginja, J.; Coutinho, M.; Ribeiro, C.; Karatzas, K.; Sioumis, T.H.; Katsifarakis, N.; Konstantinidis, K.; De Vito, S.; Esposito, E.; et al. Assessment of air quality microsensors versus reference methods: The EuNetAir joint exercise. Atmos. Environ. 2018, 147, 246-263. [CrossRef]

40. Bigi, A.; Mueller, M.; Grange, S.K.; Ghermandi, G.; Hueglin, C. Performance of NO, $\mathrm{NO}_{2}$ low cost sensors and three calibration approaches within a real world application. Atmos. Meas. Tech. 2018. [CrossRef]

41. Cordero, J.M.; Borge, R.; Narros, A. Using statistical methods to carry out in field calibrations of low cost air quality sensors. Sens. Actuator B Chem. 2018, 267, 245-254. [CrossRef]

42. Wen, L.; Xue, L.K.; Wang, X.F.; Xu, C.H.; Chen, T.S.; Yang, L.X.; Wang, T.; Zhang, Q.Z.; Wang, W.X. Summertime fine particulate nitrate pollution in the North China Plain: Increasing trends, formation mechanisms and implications for control policy. Atmos. Chem. Phys. 2018, 18, 11261-11275. [CrossRef]

43. Xue, L.K.; Ding, A.J.; Gao, J.; Wang, T.; Wang, W.X.; Wang, X.Z.; Lei, H.C.; Jin, D.Z.; Qi, Y.B. Aircraft measurements of the vertical distribution of sulfur dioxide and aerosol scattering coefficient in China. Atmos. Environ. 2010, 44, 278-282. [CrossRef]

44. Shen, X.J.; Sun, J.Y.; Zhang, X.Y.; Kivekas, N.; Zhang, Y.M.; Wang, T.T.; Zhang, X.C.; Yang, Y.; Wang, D.Z.; Zhao, Y.; et al. Particle Climatology in Central East China Retrieved from Measurements in Planetary Boundary Layer and in Free Troposphere at a 1500-m-High Mountaintop Site. Aerosol Air Qual. Res. 2016, 16, 689-701. [CrossRef]

45. Sun, L.; Xue, L.K.; Wang, Y.H.; Li, L.L.; Lin, J.T.; Ni, R.J.; Yan, Y.Y.; Chen, L.L.; Li, J.; Zhang, Q.Z.; et al. Impacts of meteorology and emissions on summertime surface ozone increases over central eastern China between 2003 and 2015. Atmos. Chem. Phys. 2019, 19, 1455-1469. [CrossRef]

46. Sun, L.; Xue, L.K.; Wang, T.; Gao, J.; Ding, A.J.; Cooper, O.R.; Lin, M.Y.; Xu, P.J.; Wang, Z.; Wang, X.F.; et al. Significant increase of summertime ozone at Mount Tai in Central Eastern China. Atmos. Chem. Phys. 2016, 16, 10637-10650. [CrossRef]

47. Yang, X.; Xue, L.K.; Yao, L.; Li, Q.Y.; Wen, L.; Zhu, Y.H.; Chen, T.S.; Wang, X.F.; Yang, L.X.; Wang, T.; et al. Carbonyl compounds at Mount Tai in the North China Plain: Characteristics, sources, and effects on ozone formation. Atmos. Res. 2017, 196, 53-61. [CrossRef]

48. Gao, J.; Wang, T.; Ding, A.J.; Liu, C.B. Observational study of ozone and carbon monoxide at the summit of mount Tai (1534 m a.s.l.) in central-eastern China. Atmos. Environ. 2005, 39, 4779-4791. [CrossRef]

49. Xue, L.K.; Wang, T.; Zhang, J.M.; Zhang, X.C.; Deliger; Poon, C.N.; Ding, A.J.; Zhou, X.H.; Wu, W.S.; Tang, J.; et al. Source of surface ozone and reactive nitrogen speciation at Mount Waliguan in western China: New insights from the 2006 summer study. J. Geophys. Res.Atmos. 2011, 116, 12. [CrossRef] 
50. Wen, L.; Chen, T.S.; Zheng, P.G.; Wu, L.; Wang, X.F.; Mellouki, A.; Xue, L.K.; Wang, W.X. Nitrous acid in marine boundary layer over eastern Bohai Sea, China: Characteristics, sources, and implications. Sci. Total Environ. 2019, 670, 282-291. [CrossRef]

51. Leduc, D.J. A comparative-analysis of the reduced major axis technique of fitting lines to bivariate data. Can. J. For. Res. 1987, 17, 654-659. [CrossRef]

52. Breiman, L. Random Forests. Mach. Learn. 2001, 45, 5-32. [CrossRef]

53. Zimmerman, N.; Presto, A.A.; Kumar, S.P.N.; Gu, J.; Hauryliuk, A.; Robinson, E.S.; Robinson, A.L.; Subramanian, R. A machine learning calibration model using random forests to improve sensor performance for lower-cost air quality monitoring. Atmos. Meas. Tech. 2018, 11, 291-313. [CrossRef]

C 2020 by the authors. Licensee MDPI, Basel, Switzerland. This article is an open access article distributed under the terms and conditions of the Creative Commons Attribution (CC BY) license (http://creativecommons.org/licenses/by/4.0/). 